\title{
ANALISIS PERBANDINGAN KURVA HAZARD PADA KOTA MANOKWARI DENGAN SUMBER GEMPA SESAR SORONG \\ DAN MENGGUNAKAN BEBERAPA FUNGSI ATENUASI \\ Tria Fitri Yani ${ }^{1)}$, Hamdan Solihin ${ }^{2)}$ \\ Perwira Budiman $^{3)}$, Imam Trianggoro Saputro ${ }^{4)}$ \\ 1),2),3),4)Program Studi Teknik Sipil, Universitas Muhammadiyah Sorong \\ Email : dhaniak31@gmail.com
}

\begin{abstract}
Abstrak
Pulau Papua Barat adalah sebuah provinsi di Indonesia yang terletak diujung barat Pulau Papua yang ibukotanya adalah Manokwari. Resiko gempa bumi pada wilayah ini tergolong tinggi, hal ini disebabkan karena Papua Barat terdapat sebanyak 150 sesar dan beberapa diantaranya cukup rawan seperti sesar Sorong dan Manokwari Selatan. Pada penelitian ini melakukan analisis kurva hazard untuk mengetahui berapa besar percepatan tanah (ground acceleration) yang terjadi akibat gempa bumi pada wilayah Manokwari dengan berbagai macam jarak. Kurva Hazard dianalisis menggunakan fungsi atenuasi patwardan dkk (1978), crouse (1987), Campbell (1981), dan Campbell (1993). Dari hasil penilitian menunjukkan besar nilai percepatan tanah (ground acceleration) akan meningkat seiring dengan besarnya nilai kala ulang (return periode) yang diperhitungkan. Kurva Hazard pada daerah Kota Manokwari akibat sesar Sorong akan menunjukkan nilai terbesar pada sat menggunakan fungsi atenuasi Crouse (1987) sedangkan yang terkecil adalah menggunakan fungsi atenuasi Campbell (1981).
\end{abstract}

Kata Kunci : Kurva Hazard, Atenuasi, Sesar Sorong , Kota Manokwari.

\section{PENDAHULUAN}

Tektonik Papua saat ini dipengaruhi oleh pergerakan 2 lempeng besar, yaitu llempeng Pasifik kearah barat dan lempeng Indonesia-Australia yang kearah utara dengan jalur subduksi terdapat di perairan utara papua sampai perairan utara biak dan perairan barat Fakfak sampai perairan selatan kaimana. Sesar Sorong merupakan retakan besar dalam kerak bumi dan selama 40 juta tahun telah melepaskan potongan daratan yang luas dari Papua sebelah utara dan pulau-pulau yang terbentuk karena adanya sesar ini bergeser ke arah barat melintasi lautan ke arah Sulawesi. 


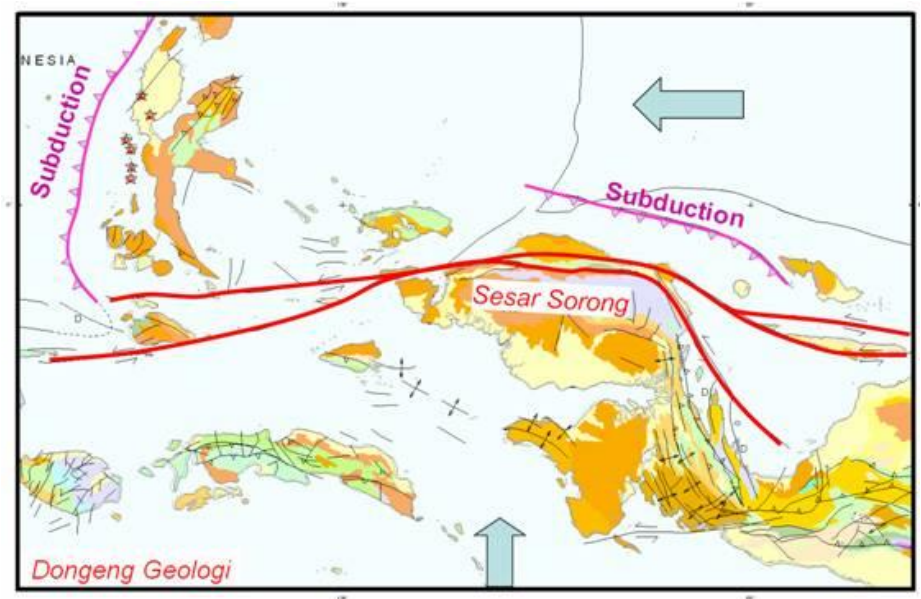

\section{Pembahasan}

Ada beberapa metode yang dapat digunakan dalam Seismic Hazard Assessment untuk membuat prediksi kejadian gempa di masa yang akan datang (gempa rencana). Metode-metode itu diantaranya adalah The Gumbel Type I method, The Line Source Method, The Total Probability Area Method dan The EQ Occurrence Distributed.

Pada tugas kali ini, Seismic Hazard Assessment menggunakan The Line Source Method untuk membuat Hazard curve yang dapat memperkirakan kejadian gempa di kota akibat aktifitas Sesar Renun. Rumus Atenuasi yang digunakan adalah Patwardan dkk (1978), Campbell (1981), Crouse (1987) dan Campbell (1993). Kota Manokwari terletak pada koordinat $0^{\circ}$ $5^{\prime}{ }^{\prime} \mathrm{LU} 134^{\circ} 05^{\prime} \mathrm{BT} / 0,867^{\circ} \mathrm{LS} 134,083^{\circ} \mathrm{BT}$

\section{Metode}

Refensi dalam penelitian ini mengikuti Widodo (2012), Douglas (1991) dan Imam (2018). Untuk urutan metode yang digunakan dalam penelitian ini adalah sebagai berikut:

a. Mengidentifikasi koordinat kota Sorong.

b. Menganalisis jarak maks. 100km dari titik episenter gempa bumi yang akan terjadi.

e. Menganalisis percepatan tanah dengan menggunakan beberapa fungsi atenuasi

f. Membuat kurva hazard hasil dari analisis.

g. Kesimpulan 


\section{Menghitung Fungsi Atenuasi}

Pada analisis resiko gempa apabila lokasi yang ditinjau (site interest) tidak mempunyai data rekaman gempa maka untuk memperkirakan besarnya percepatan maksimum tanah digunakan fungsi atenuasi. Yang dimaksud dengan fungsi atenuasi adalah suatu fungsi yang menggambarkan koreksi antara intensitas(i) gerakan tanah setempat, magnitude (M) dan Jarak (R) dari sumber titik dalam daerah sumber gempa. Memperkirakan fungsi atenuasi untuk gerakan tanah akibat gempa telah menjadi subjek yang menarik dalam mengaplikasikan resikokegempaan dalam perencanaan bangungan tahan gempa. Faktor - faktor yang mempengaruhi fungsi atenuasi adalah :

1. Mekanisme Gempa

2. Jarak Episenter

3. Kondisi Tanah Lokal

\section{ATENUASI PATWARDAN DKK (1978)}

Rumus Atenuasi Patwardan dkk:

$$
\begin{aligned}
& \operatorname{Ln} Y=\operatorname{Ln}(157)+1.04 x M s-1.9 \times \operatorname{Ln}\left(R+0.864 x e^{0.463 M s}\right) \\
& \text { Dimana : } \quad \text { e } \quad=2,718282 \\
& \mathrm{M} \quad=5,4 \\
& \mathrm{R}=1 \mathrm{~km} \\
& \operatorname{Ln} Y=\operatorname{Ln}(157)+1.04 x M s-1.9 x \operatorname{Ln}\left(R+0.864 x e^{0.463 M s}\right) \\
& \operatorname{Ln} Y=\operatorname{Ln}(157)+1.04 \times 5.4-1.9 \times \operatorname{Ln}\left(1+0.864 \times 2.718282^{0.463 \times 5.4}\right) \\
& Y=6.027202 \\
& \operatorname{Ln}=(6.027202) \\
& =1.796282925
\end{aligned}
$$


Berdasarkan persamaan tersebut diatas maka diperoleh kurva hazard seperti yang terlihat pada Gambar berikut :

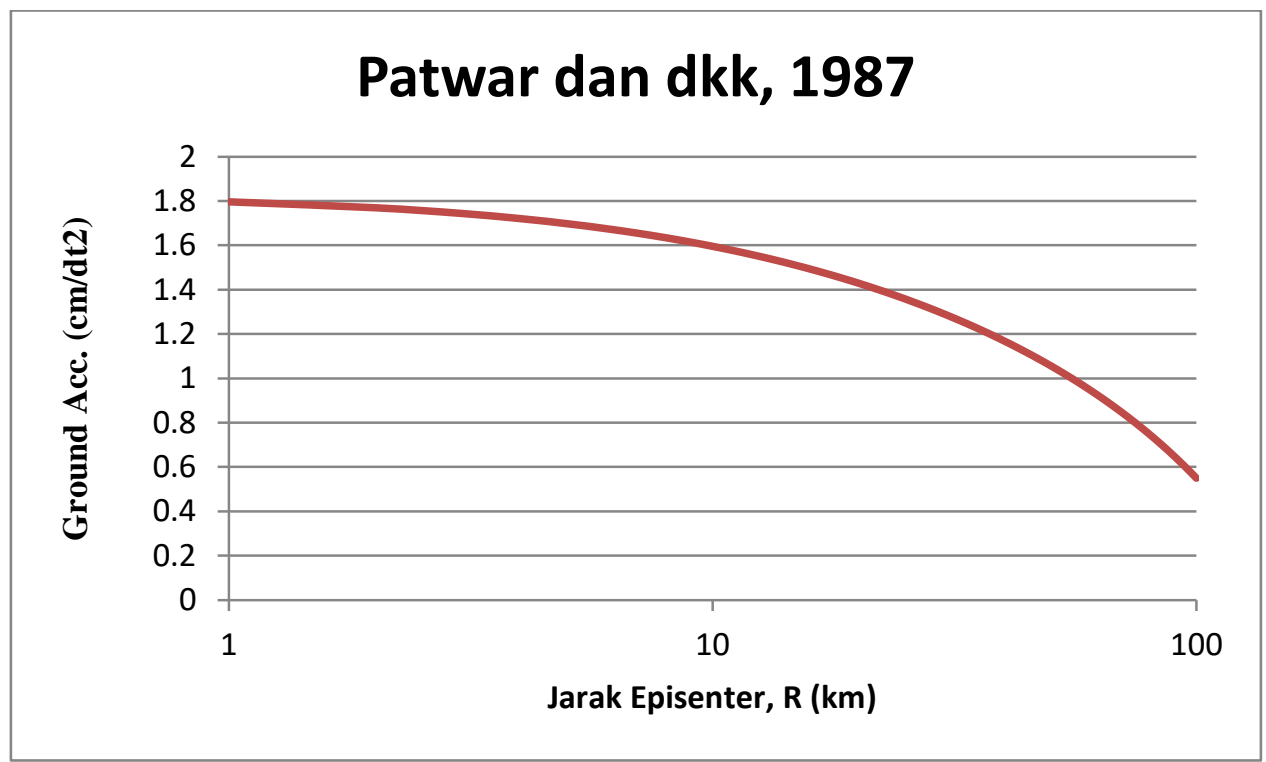

\section{ATENUASI CROUSE (1987)}

Rumus Atenuasi Crouse:

$\operatorname{Ln} Y=2,4846+0,7334 \times M)-\left(0,0151\left(M^{2}\right)-(0,5056 \times \operatorname{Ln}(R+1))\right)-(0,0094 \times R)$

Dimana $\quad: M=5,4$

$\mathrm{R}=1 \mathrm{~km}$ 
Perhitungan :

$$
\begin{aligned}
\operatorname{Ln} Y & =2,4846+0,7334 \times 5,4)-\left(0,0151\left(5,4^{2}\right)-(0,5056 \times \operatorname{Ln}(1+1))\right)-(0,0094 \times 1) \\
Y & =24849,86 \\
\operatorname{Ln} & =(24849,86) \\
& =10,12061
\end{aligned}
$$

Berdasarkan persamaan tersebut diatas maka diperoleh kurva hazard seperti yang terlihat pada Gambar berikut :

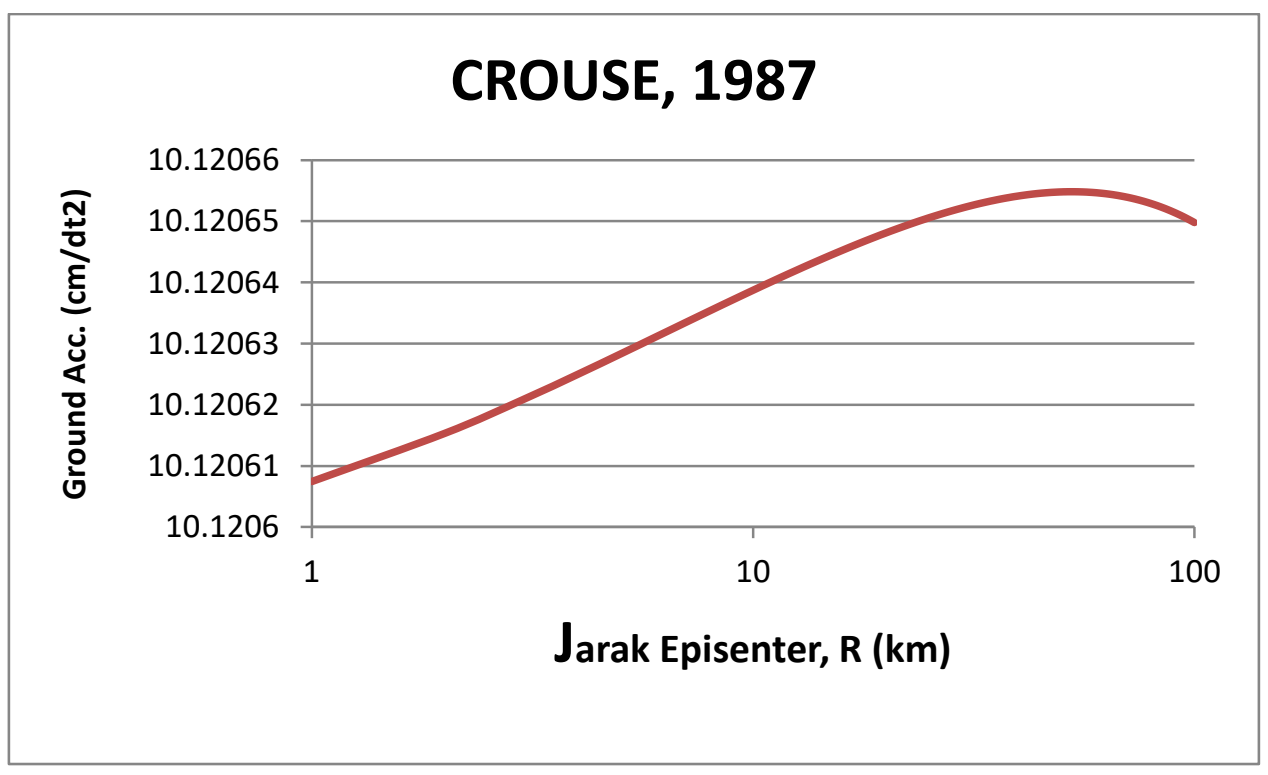

\section{ATENUASI CAMPBELL (1981)}

Rumus Atenuasi Campbell:

$$
Y=0,0159 x e^{(0,0868 \times M) x\left(R+0,0606 x e^{(0,7 x M))^{-1,09}}\right.}
$$

Dimana : $\quad e=2,718282$

$$
\mathrm{M}=5,4
$$




$$
\mathrm{R}=1 \mathrm{Km}
$$

Perhitungan :

$$
\begin{aligned}
Y & =0,0159 \times e^{(0,0868 \times M) x\left(R+0,0606 \times e^{(0,7 \times M))^{-1,09}}\right.} \\
& =0,0159 \times 2,718282^{(0,0868 \times 5,4) x\left(1+0,0606 \times 2,718282^{(0,7 \times 5,4))^{-1,09}}\right.} \\
& =0,420187
\end{aligned}
$$

Berdasarkan persamaan tersebut diatas maka diperoleh kurva hazard seperti yang terlihat pada Gambar berikut :

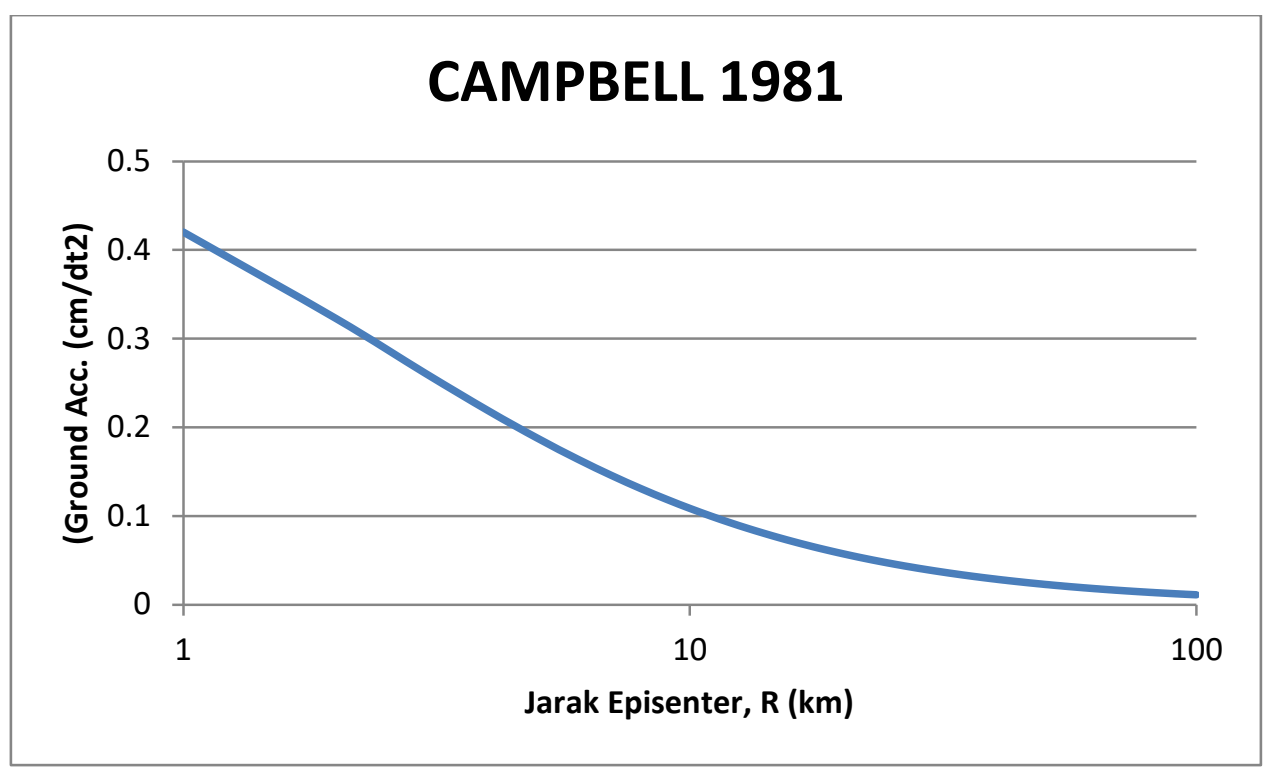

\section{ATENUASI CAMPBELL (1981)}

Rumus Atenuasi Campbell:

$$
\begin{aligned}
\operatorname{Ln} Y=-3,15 & +0,683 x M)-\operatorname{Ln}\left(R^{2}+\left(0,0586 e^{(0,683 M)}\right)^{2}\right)^{0,5}-(0,015-0,000995) R \\
& +0,27 x F+(-0,105 \operatorname{Ln}(R)) S
\end{aligned}
$$

Dimana : 


$$
\begin{gathered}
\begin{array}{l}
\mathrm{e}=2,718282 \quad \mathrm{~S}=1 \\
\mathrm{M}=5,4 \\
\mathrm{R}=1 \mathrm{Km}
\end{array} \\
\begin{array}{c}
\operatorname{Ln} Y=-3,15+0,683 \times 5,4)-\operatorname{Ln}\left(1^{2}+\left(0,0586 \times 2,718282^{(0,683 \times 5,4)}\right)^{2}\right)^{0,5} \\
\quad-(0,015-0,000995) 1+0,27 \times 1+(-0,105 \operatorname{Ln}(1)) 1
\end{array} \\
=-0,5732 \\
\operatorname{Ln}=-0,5732 \quad=-0,5565131
\end{gathered}
$$

Berdasarkan persamaan tersebut diatas maka diperoleh kurva hazard seperti yang terlihat pada Gambar berikut :

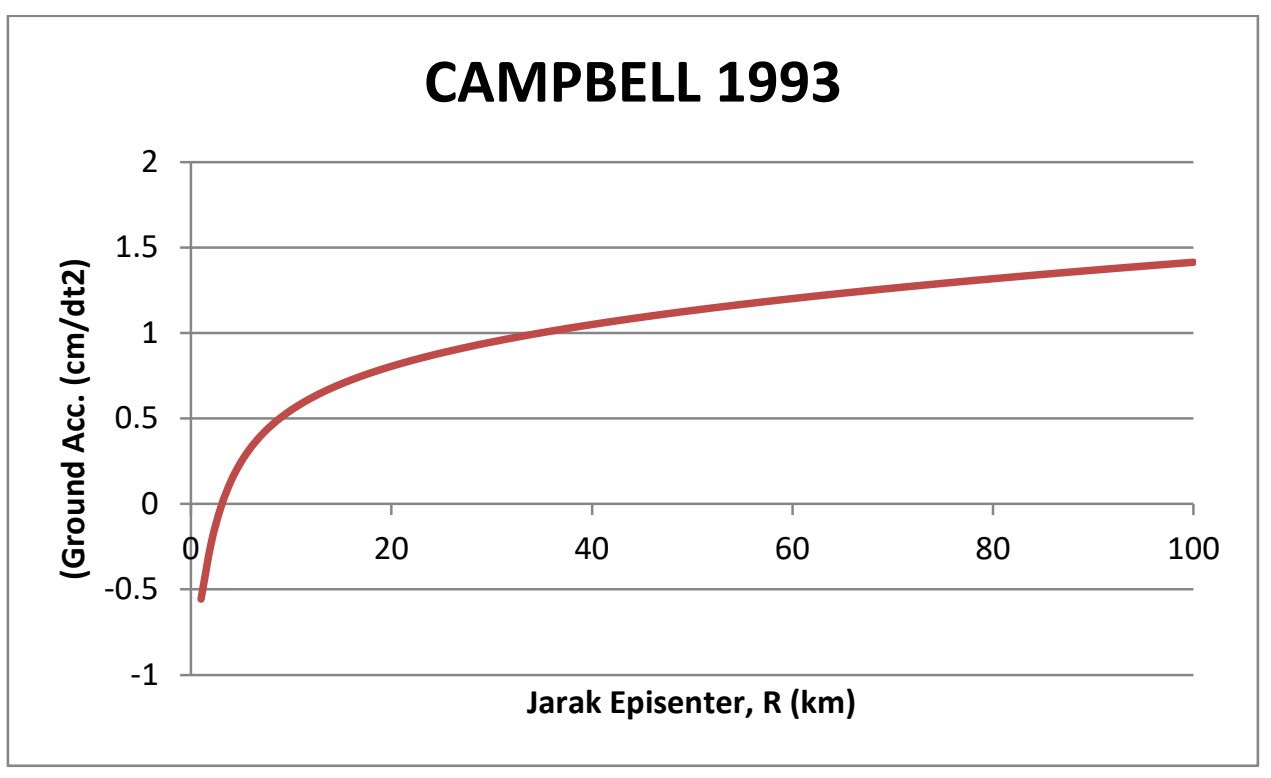

\section{Perbandingan Fungsi-Fungsi Atenuasi}

Setelah melakukan analisis dengan menggunakan fungsi atenuasi fungsi atenuasi Patwar dan dkk (1987), Crouse 1987, Campbell (1981) dan Campbell (1993), di atas maka diperoleh hasil kurva hazard seperti yang tersaji pada Gambar berikut ini. 


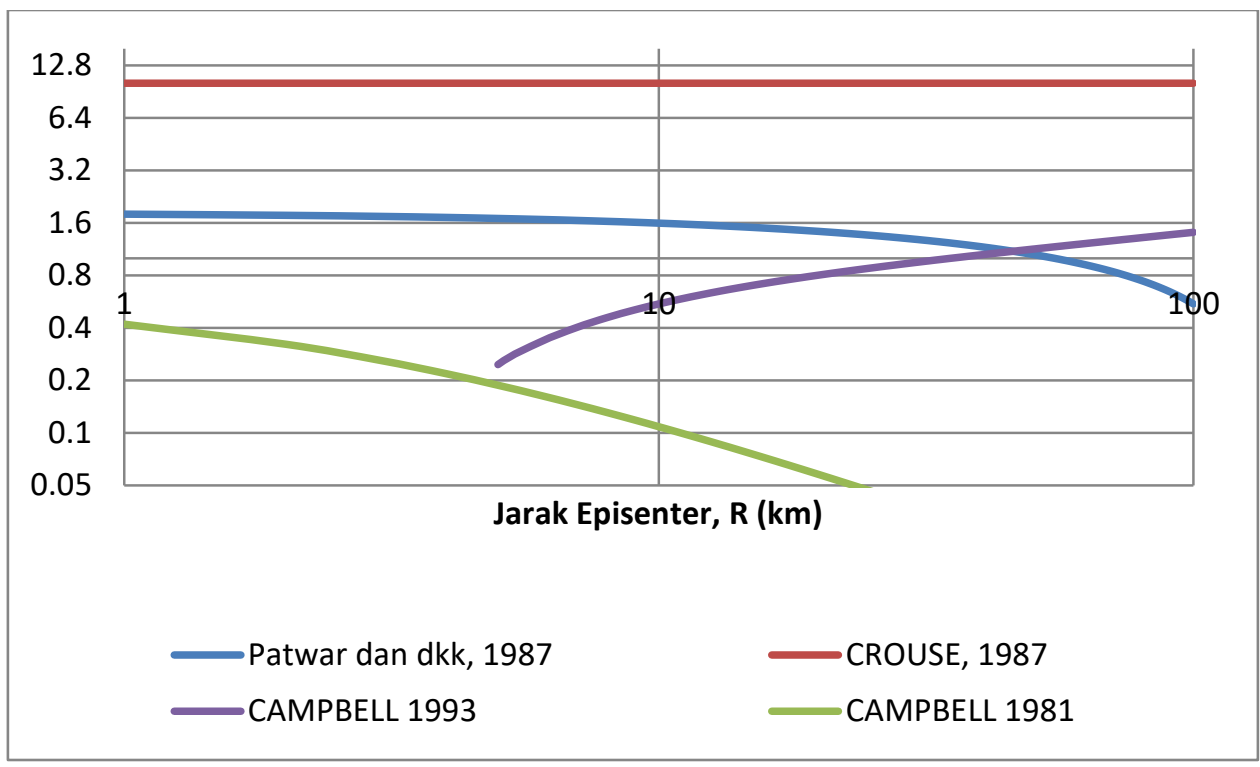

Berdasarkan hasil Gambar di atas menunjukkan besarnya nilai percepatan tanah (ground acceleration) akan meningkat seiring dengan besarnya jarak yang diperhitungkan. Hasil penelitian menunjukkan bahwa kurva hazard menunjukkan nilai terbesar pada saat menggunakan fungsi atenuasi Crouse (1987) sedangkan nilai terkecil pada kurva hazard terjadi pada saat menggunakan fungsi atenuasi Campbell (1981).

Kurva hazard ini dapat digunakan dalam menentukan besarnya percepatan tanah di daerah kota Manokwari yang disebabkan oleh sumber gempa sesar. Hal ini juga dapat dianggap sebagai langkah mitigasi. Upaya mitigasi perlu dilakukan untuk mengidentifikasi bencana yang akan terjadi dikemudian hari dengan mengambil langkah antisipasi. Hal ini dilakukan dalam rangka untuk mengurangi resiko yang ditimbulkan sehingga tingkat kerugian dan korban yang berjatuhan dapat diminimalisir.

\section{Kesimpulan}

Berdasarkan hasil penelitian maka diperoleh beberapa kesimpulan sebagai berikut ini:

1. Besarnya nilai percepatan tanah (ground acceleration) akan meningkat seiring dengan besarnya nilai jarak yang diperhitungkan.

2. Kurva hazard pada Gempa kota Manokwari akibat sesar sorong akibat sesar akan menunjukkan nilai terbesar pada saat menggunakan fungsi atenuasi Crouse (1987). Sedangkan nilai terkecil pada saat menggunakan fungsi atenuasi Campbell (1981). 
Daftar pustaka

Prof. Ir. Widodo, MSCE, PhD , 2012, Atenuasi Gerakan Tanah dan Atenuasi Intensitas Gempa, Universitas Islam Indonesia, Yogyakarta

Imam Saputra Trianggoro, Analisis Perbandingan Kurva hazard pada kota Banda Aceh dengan sumber gempa Sesar Seulimeum dan menggunakan beberapa fungsi Atenuasi, Program Studi teknik Sipil, Universitas Muhammadiyah Sorong, Sorong 